\title{
A Model of the Effect of Pseudothecia on Genetic Recombination and Epidemic Development in Populations of Mycosphaerella graminicola
}

\author{
L. Eriksen, M. W. Shaw, and H. Østergård
}

\begin{abstract}
First author: Plant Biology and Biogeochemistry Department, Ris $\emptyset$ National Laboratory, DK-4000 Roskilde, Denmark, and The Royal Veterinary and Agricultural University, DK-1873 Frederiksberg C, Denmark; second author: Department of Agricultural Botany, School of Plant Sciences, The University of Reading, Whiteknights, Reading RG6 6AU, England; and third author: Plant Biology and Biogeochemistry Department, Ris $\emptyset$ National Laboratory, DK-4000 Roskilde, Denmark.
\end{abstract}

Accepted for publication 27 November 2000.

\begin{abstract}
Eriksen, L., Shaw, M. W., and Østergård, H. 2001. A model of the effect of pseudothecia on genetic recombination and epidemic development in populations of Mycosphaerella graminicola. Phytopathology 91:240-248.

It is generally agreed that ascospores are the origin of primary infections for the disease septoria tritici blotch of wheat caused by the fungus Mycosphaerella graminicola (anamorph Septoria tritici). The epidemic during the growing season was previously ascribed to the asexual pycnidiospores dispersed over short distances by rain splash, but recent observations suggest that the airborne ascospores also may play a role. As a consequence, the composition of the pathogen population over the growing

season may change through genetic recombination. In an attempt to resolve the relative importance of the two spore types to the epidemic over the growing season, a model simulating disease caused by both types of spores was constructed and analyzed. The conclusion from the analysis of this model is that sexual recombination will affect the genetic composition of the population during a growing season. A considerable proportion of spores released at the end of the growing season may be sexual descendants of the initial population. However, ascospores are unlikely to affect the severity of the epidemic during the growing season. This is due to the much longer latent period for pseudothecia compared with pycnidia, resulting in ascospores being produced too late to influence the epidemic.
\end{abstract}

The fungus Mycosphaerella graminicola (anamorph Septoria tritici) is the cause of the disease septoria tritici blotch of wheat. A number of studies have established that ascospores produced in pseudothecia are an important agent of primary inoculum for the infection of emerging wheat plants $(25,28)$. Recently, ascospores have been caught in the air over several seasons in the U.K., and peaks of ascospore release found during July and August, as well as during the period of crop emergence (17). In the United States, evidence for sexual reproduction during the growing season was obtained by studying the evolution of a $M$. graminicola population with molecular markers (4). These studies provided important evidence for the presence of ascospores and sexual reproduction throughout the growing season. The results suggest that ascospores together with pycnidiospores contribute to the epidemic development of septoria tritici blotch. Sexual reproduction in $M$. graminicola populations could have important consequences potentially increasing the rate of adaptation to resistant host cultivars, as well as influencing the epidemic development over the growing season. The studies mentioned above did not provide information on (i) the size of the relative contribution of ascospores compared with pycnidiospores to the epidemic development and (ii) the extent of genetic recombination. An attempt to solve the second of these problems with molecular markers has been made (32). The proportion of sexual recombinants of an artificially inoculated founder population was estimated at $24 \%$ at the end of the growing season (32). However, the reliability of this estimate was recently questioned $(2,33)$.

A comparison of the relative importance of ascospores and pycnidiospores during an epidemic of septoria tritici blotch is

Corresponding author: L. Eriksen; E-mail address: lars.eriksen@risoe.dk

Publication no. P-2001-0103-01R

(C) 2001 The American Phytopathological Society complicated because the epidemiological parameters for the two stages of the fungus differ. The latent period is considerably longer for the pseudothecia than for the pycnidia $(8,17,18)$. Due to dispersal by wind, ascospores may be dispersed over much longer distances than the splash-dispersed pycnidiospores that are restricted to the immediate surroundings of their release $(28,29)$. Furthermore, a pycnidium holds many more spores than a pseudothecium. Estimates range from 4,000 to more than 20,000 spores per pycnidium, depending on environment and cultivar $(9,15)$. A pseudothecium contains only a few hundred spores (8). Ascospores could have an advantage over pycnidiospores, because dispersal may occur during relatively dry periods when dispersal of pycnidiospores is restricted. Consequently, the relative importance of the different factors for the epidemic development of the $M$. graminicola population is not clear.

The objective of this paper is to study by simulation the influence of the ascospores of $M$. graminicola on epidemics of septoria tritici blotch. Dynamic models simulating disease in wheat crops have been developed for $M$. graminicola and a pathogen with a similar disease cycle, Phaeosphaeria nodorum, which causes the disease stagonospora nodorum blotch $(7,22,23)$. However, these models only include pycnidiospores as inoculum, disregarding the influence of ascospores on the epidemic. It was therefore necessary to develop a new model taking account of both pycnidiospores and ascospores.

\section{THEORY AND APPROACHES}

Biological assumptions. In the present model, the population of the pathogen is defined as the amount of diseased leaf area in three classes, latent, infectious, and exhausted (postinfectious). It is thus unnecessary to account for individuals of the fungus or for fruit bodies directly. Previously, an individual of $M$. graminicola was defined as a mycelium of the same genotype growing inside the leaf, initiated by one infection (27). This mycelium will pro- 
duce asexual fruit bodies, pycnidia, when it encounters a substomatal chamber, so one individual produces a number of pycnidia $(5,16,19)$. The fungus probably has a bipolar heterothallic mating system (18), so two different mating types have to meet for the production of the sexual fruit bodies, which are pseudothecia. In the model, it is assumed that the meeting of two individuals of opposite mating type will always lead to the production of pseudothecia. No special conditions, such as particular environmental factors, are necessary.

Host leaf area is modeled with a crop growth model. The exact shape of the curve for host leaf area will influence the disease severity, but the dynamics between the two spore types of the fungus are unlikely to be affected. The host leaf area either senesces naturally or it is infected by ascospores or pycnidiospores. Primary infections are initiated by ascospores immigrating from outside, and it is assumed that the immigration continues during the entire growing season. After the latent period for pycnidia, a part of the area of latent disease becomes infectious, producing pycnidiospores, and the remaining area continues the latency for a period after which infectious pseudothecia appear. The leaf area allocated to the production of pseudothecia was assumed to depend on the size of the latent diseased leaf area relative to the total leaf area. This is related to the infection density. The higher the infection density, the higher the probability that two individuals of different mating type meet in the leaf and initiate the production of pseudothecia. The infectious leaf area produces spores for an infectious period, after which the leaf area is assumed to be exhausted. The areas with infectious pycnidia and pseudothecia determine, together with the respective multiplication efficiencies for pycnidia and pseudothecia, the size of the potential newdiseased area produced per time unit. The actual area becoming diseased is the potential-diseased area reduced in proportion to the available healthy leaf area. The assumption of a longer period from infection to sporulation for pseudothecia compared with pycnidia is based on monocyclic infection experiments $(17,18)$ as well as monitoring of natural epidemics in the field (8), where pseudothecia always appeared much later than pycnidia.

The model keeps track of how much leaf area is infected by sexual descendants of the immigrant ascospores that established the disease in the field, and how much is infected by asexual descendants, descending directly via pycnidial generations from the immigrants.

The biological parameters in the model are based on thermal time (degree days). This was chosen because it allows time constants (latent period and infectious period) to be assumed constant over the season. The use of thermal time requires that the time constants for the development of $M$. graminicola and the growth rate of the wheat host are proportional with temperature. This is approximately true for the latent period of $M$. graminicola in the temperature range 0 to $17^{\circ} \mathrm{C}(26)$ and for the growth rate of wheat over a similar range (10). The minor deviations that occur are unlikely to affect the qualitative conclusions of this paper.

Model description. In the following, the structure and parameters of the model are described. The structure of the model is shown in Figure 1, definition of variables and parameters are given in Tables 1 and 2 , and the differential equations of the model in Table 3. The model was analyzed with the software package Model Maker (version 3, Cherwell Scientific, Oxford).

The rate of host leaf area growth (LPR) was modeled with the expolinear growth model (12). Leaf area in the model has the unit of area per ground area. A number of state variables were defined corresponding to the different classes of leaf tissue. Healthy leaf area (HLAT) consists of a number of age classes, $\operatorname{HLA}_{j}(j=1$, $2, \ldots, 15)$. Latent diseased leaf area $\left(\mathrm{LDIT}_{i}\right)$ similarly consists of age classes, $\operatorname{LDI}_{i, j}(j=1,2, \ldots, 15)$, that are subdivided into area infected by asexual descendants $(i=a)$ or sexual descendants $(i=s)$ of the immigrant ascospores. The sum of asexual and sexual descendants is denoted by $i=a+s$. The state variable for immature pseudothecia (IMST) consists of age classes $\operatorname{IMS}_{j}(j=1,2)$. This variable holds the latent leaf area that has been allocated to the production of pseudothecia. Area with infectious pycnidia is designated $\operatorname{IPY}_{i}(i=a, s, a+s)$, and the area with infectious pseudothecia, IPS. Finally, naturally senesced leaf area is accounted for by the state variable NEC, and postinfectious exhausted leaf area by the state variable EXH.

The age classes for state variables HLAT, $\mathrm{LDIT}_{i}$, and IMST were included to simulate the temporal dispersion of aging of healthy leaf area and of the appearance of leaf area with infectious pycnidia (IPY), immature pseudothecia (IMST), and infectious pseudothecia (IPS). The method is based on the fixed boxcar train (14). The coefficient of variation for the delay caused by a boxcar train is given by $N^{-1 / 2}$, where $N$ is the number of age classes (boxcars) in the train (14). The more age classes for a given average delay (latent period, leaf lifetime) the lower the variation in the delay of the leaf area passing the boxcar train. LDIT $_{i}$ and HLAT are modeled with 15 age classes, to achieve a low variation in the delay, ensuring that no leaf area sporulates immediately after infection and that no healthy leaf area senesces immediately. IMST is modeled with only two age classes because it is assumed that the variation in the time from pycnidial sporulation to the appearance of sporulating pseudothecia is relatively large compared with the variation in the latent period for pycnidia. No boxcars were needed for infectious leaf area. This is because pycnidia are exhausted like an exponential distributed decay (9), and the same was assumed to be the case for pseudothecia. In the model leaf area, entering an infectious class will leave the class following an exponential decay.

It was assumed that the number of matings is proportional to the number of encounters between the two mating types and that the two mating types are mixed homogeneously on the infected leaf area. This leads to a simple mass action process (1), in which the number of matings is given by $\left[C O N \times \mathrm{LDI}_{a+s, 15} /(2 \times \mathrm{TOT})\right]$ $\times \mathrm{LDI}_{i, 15}$ (Table 3, equation 7), where $C O N$ is a contact rate. This

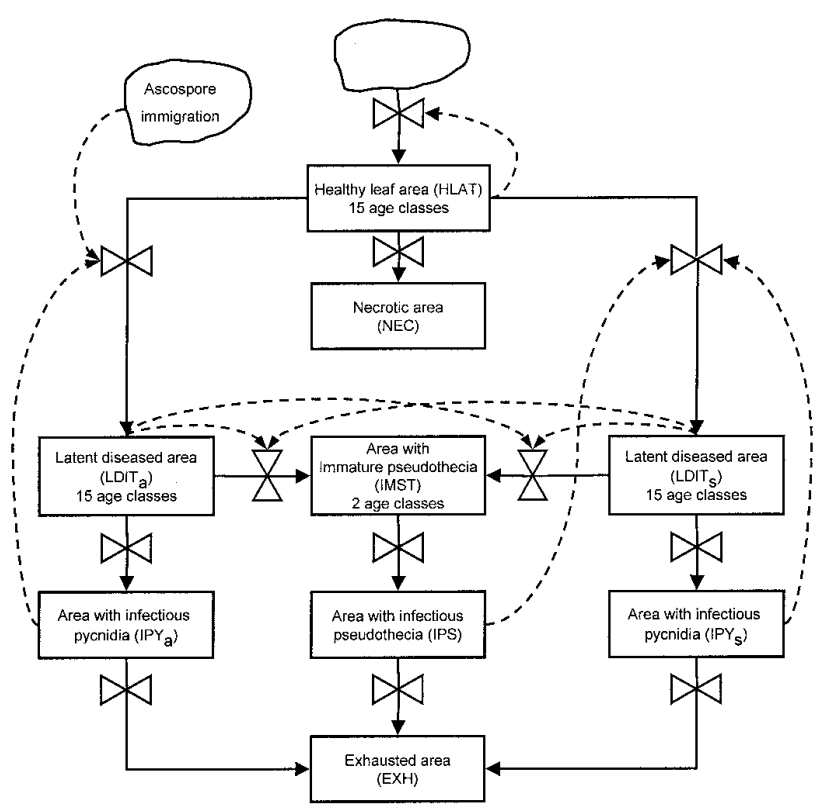

Fig. 1. Flow diagram for the model simulating the epidemic development of septoria tritici blotch, caused by pycnidiospores and ascospores of the fungus Mycosphaerella graminicola. State variables are shown in rectangular boxes and rates are shown as valve symbols. Flows of leaf area are indicated with solid arrows, and effects of state variables on rates are indicated by broken arrows. A subscript $i(=a$ or $s$ ) on state variables denotes that the variable represents leaf area infected by asexual or sexual descendants of the immigrant $M$. graminicola population. 
is the amount of $\mathrm{LDI}_{i, 15}$ becoming occupied by immature pseudothecia per unit of time. The flow from latent diseased leaf area to area with immature pseudothecia $\left(\mathrm{IMS}_{1}\right)$ thus depends on the size of the latent diseased leaf area in $\mathrm{LDI}_{i, 15}$ relative to the total leaf area (TOT). Leaf area with immature pseudothecia become leaf area with sporulating pseudothecia after a further delay, $L P_{p s}$. Leaf area occupied by infectious pycnidia and infectious pseudothecia become exhausted $(\mathrm{EXH})$ after an infectious period $\left(I P_{p y}\right.$ and $\left.I P_{p s}\right)$ (Table 3, equation 12).

Due to immigration into the field via airborne ascospores, healthy leaf area becomes diseased and moves into $\mathrm{LDI}_{a, 1}$ at a constant rate $(I M M)$ (Table 3, equations 1, 2, and 4). In addition to immigration, disease is initiated on healthy leaf tissue in proportion to the infectious area and the two parameters for multiplication efficiency, one for leaf area with pycnidia $\left(M E_{p y}\right)$ and one for leaf area with pseudothecia $\left(M E_{p s}\right)$ (Table 3, equations 1 and 2). The multiplication efficiency describes how much new leaf area is infected per infectious area per healthy area per time unit. The definition of this parameter as per healthy leaf area is based on the assumption that the probability of a spore landing on healthy host tissue is proportional to the area available.

The output from the model was defined in a number of auxiliary variables (Table 1). The total leaf area that is neither exhausted nor naturally senesced is designated TOT. The area under the disease progress curve (AUDPC ${ }_{2,500}$ ) measures the integrated severity of the epidemic up to $2,500^{\circ} \mathrm{C}$-day, with the instantaneous disease severity being the fraction of leaf area diseased, including latent disease. Spore equivalents are a measure of the contribution of a particular type of spore to current new infections, calculated as $M E_{p y} \times \mathrm{IPY}_{a+s}$ for area with pycnidia and $M E_{p s} \times$ IPS for area with pseudothecia. It allows a direct comparison of the importance of the two types of area to the epidemic progress at a given instant. The proportion of pseudothecia is the proportion of infectious leaf area that is occupied by pseudothecia, and is a quantity that can be estimated directly by examination of field samples. Two different measures of sexual descendants at a given time were defined. The proportion of sexual descendants as spore equivalents measures the proportion of potential new infections

TABLE 1. Variables in the model simulating the epidemic development of the disease septoria tritici blotch of wheat, caused by pycnidiospores and ascospores of the fungus Mycosphaerella graminicola

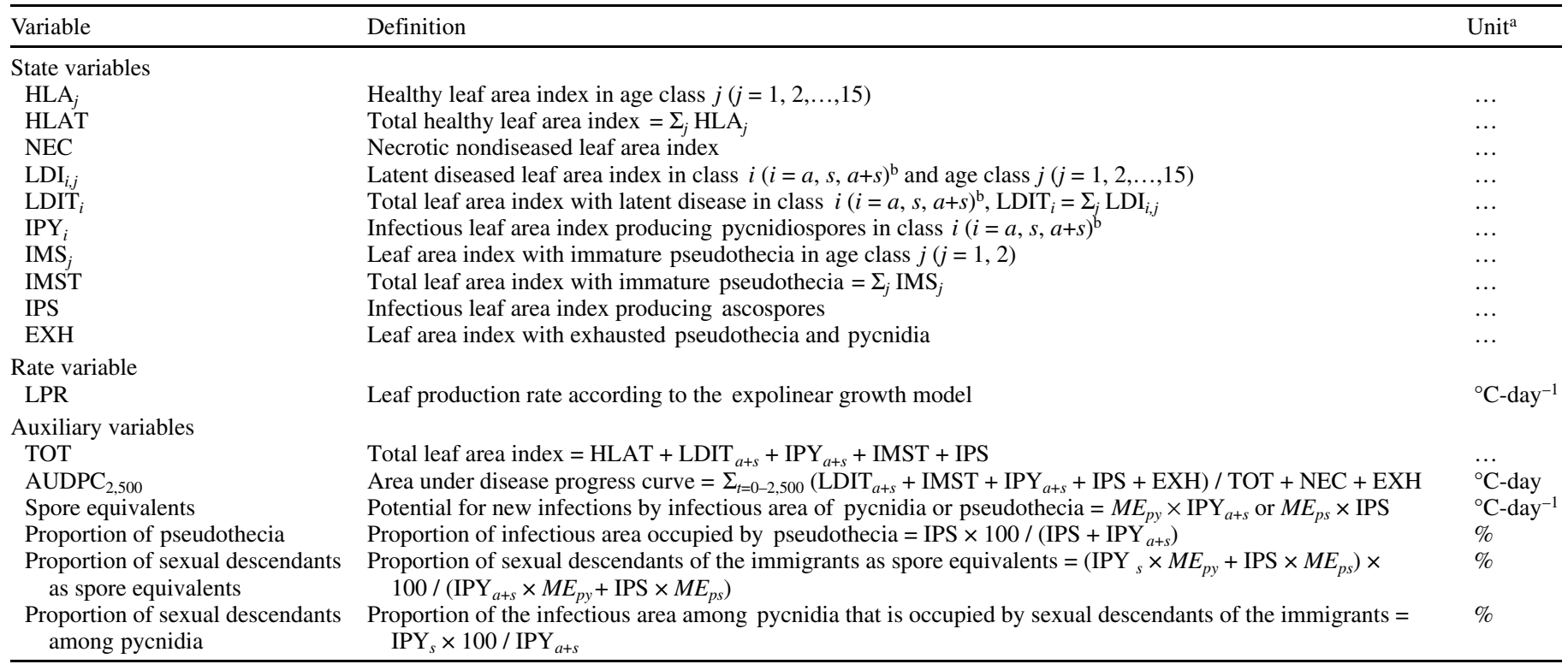

a All leaf areas in the model are relative to ground area and are therefore dimensionless (square meter of leaf per square meter of ground).

${ }^{\mathrm{b}}$ For $i=a$, the state variable represents leaf area infected by asexual descendants of the immigrant population; for $i=s$, it represents leaf area infected by sexual descendants; and for $i=a+s$, it represents leaf area infected by both asexual and sexual descendants of the immigrant population.

TABLE 2. Parameters and parameter values in the model simulating the epidemic development of the disease septoria tritici blotch of wheat, caused by pycnidiospores and ascospores of the fungus Mycosphaerella graminicola

\begin{tabular}{|c|c|c|c|}
\hline Parameter & Definition $^{\mathrm{b}}$ & Values in simulation & Unit $^{\mathrm{a}}$ \\
\hline$C$ & Derived constant, expolinear model & 0.015 & ${ }^{\circ} \mathrm{C}-$ day $^{-1}$ \\
\hline$K$ & Light extinction coefficient, expolinear model & 0.4 & $\ldots$ \\
\hline$T_{s}$ & Time after emergence for stop of growth of healthy leaf area & 1,500 & ${ }^{\circ} \mathrm{C}$-day \\
\hline$T_{l}$ & Lifetime for healthy leaf area & 700 & ${ }^{\circ} \mathrm{C}$-day \\
\hline$I M M$ & Rate of healthy leaf area becoming diseased due to immigration & $10^{-5}$ & ${ }^{\circ} \mathrm{C}-\mathrm{day}^{-1}$ \\
\hline$C O N$ & Contact rate between areas with different mating types & $0,2,4,6$ & ${ }^{\circ} \mathrm{C}-\mathrm{day}^{-1}$ \\
\hline$L P_{p y}$ & Latent period for pycnidia & $250,350,450,550$ & ${ }^{\circ} \mathrm{C}$-day \\
\hline$L P_{p s}^{P y}$ & Additional latent period for pseudothecia & $=L P_{p y} \times\left(R_{L P}-1\right)$ & ${ }^{\circ} \mathrm{C}$-day \\
\hline$R_{L P}$ & Ratio between latent periods: $\left(L P_{p s}+L P_{p y}\right) / L P_{p y}$ & $1.5,2.0,2.5,3.0$ & $\ldots$ \\
\hline$I P_{p y}$ & Infectious period for area with pycnidia & 75 & ${ }^{\circ} \mathrm{C}$-day \\
\hline$I P_{p s}$ & Infectious period for area with pseudothecia & 75 & ${ }^{\circ} \mathrm{C}$-day \\
\hline$M E_{p y}$ & Multiplication efficiency for area with pycnidia & $0.02,0.05,0.08,0.11$ & ${ }^{\circ} \mathrm{C}-\mathrm{day}^{-1}$ \\
\hline$M E_{p s}$ & Multiplication efficiency for area with pseudothecia & $=R_{M E} \times M E_{p y}$ & ${ }^{\circ} \mathrm{C}-\mathrm{day}^{-1}$ \\
\hline$R_{M E}$ & Ratio between multiplication efficiencies: $M E_{p s} / M E_{p y}$ & $0.1,0.4,0.5,0.7,1.0$ & $\ldots$ \\
\hline$H L A T_{M}$ & Maximum healthy leaf area index & 6 & $\ldots$ \\
\hline$H L A T_{I}$ & Initial healthy leaf area index & 0.2 & $\ldots$ \\
\hline
\end{tabular}

a All leaf areas in the model are relative to ground area and are therefore dimensionless (square meter of leaf per square meter of ground).

${ }^{\mathrm{b}}$ All parameters, except $C O N, L P_{p y}, R_{L P}, M E_{p y}$, and $R_{M E}$, are identical for all simulations. 
that would be initiated by spores that are sexual descendants of the immigrant ascospore population. The proportion of sexual descendants among pycnidia is the proportion of the area with infectious pycnidia that is occupied by sexual descendants of the immigrants.

Parameterization. Simulation runs were performed by the model with different values of the contact rate $(C O N)$, multiplication efficiency for leaf area occupied by pycnidia $\left(M E_{p y}\right)$, ratio between multiplication efficiencies $\left(R_{M E}\right)$, latent period for pycnidia $\left(L P_{p y}\right)$, and ratio between latent periods $\left(R_{L P}\right)$, but fixed values of the other parameters (Table 2). A subset of these simulations is shown. The contact rate was varied between 0 (no sexual reproduction) and $6^{\circ} \mathrm{C}$-day ${ }^{-1}$. However, no actual estimate of the contact rate has been found.

The ratio between the multiplication efficiency for leaf area occupied by pseudothecia and pycnidia was introduced to keep a constant ratio between the multiplication efficiencies when the multiplication efficiency for pycnidia was varied in the simulations. The multiplication efficiency for pseudothecia is unlikely to be higher than for pycnidia, because fewer spores are produced in a pseudothecium, therefore, the ratio between the multiplication efficiencies was varied from 0.1 to 1.0 . The ratio between the latent period for pseudothecia and pycnidia (both measured from the time of infection) was introduced to keep a constant ratio between the latent periods when the latent period for pycnidia was varied in the simulations. From monocyclic infection experiments $(17,18)$, this ratio can be calculated to be in the region of 2.5 to 6 , whereas field observations suggest a ratio of roughly 2 to 3 on leaves one (flag) to four (8). In the simulations, the ratio was varied between 1.5 and 3.0. The multiplication efficiency for pycnidia was varied from 0.02 to $0.11^{\circ} \mathrm{C}$ - day $^{-1}$ because this provided a wide range of disease severities independent of latent period.

Incubation period in the field was in different studies estimated from 350 to $400^{\circ} \mathrm{C}$-day and 400 to $500^{\circ} \mathrm{C}$-day, depending on cultivar and leaf layer $(22,30)$. The latent period under field conditions was estimated from 300 to $380^{\circ} \mathrm{C}$-day (26). In the simulations reported here, the latent period varied from 250 to $550^{\circ} \mathrm{C}$-day (Table 2 ). The infectious period for pycnidia $\left(I P_{p y}\right)$ was assumed to be $75^{\circ} \mathrm{C}$-day. High humidity is sufficient to make pycnidia sporulate (9), overnight dew will therefore be sufficient for the pycnidia to sporulate, ensuring regular sporulation. The number of spores released decreases exponentially with each sporulation event, but a significant amount of spores can be released on five consecutive sporulation events (9), i.e., 5 days. With an average temperature of $15^{\circ} \mathrm{C}$ and a base temperature of $0^{\circ} \mathrm{C}, 5$ days corresponds to $75^{\circ} \mathrm{C}$-day. The infectious period of pseudothecia $\left(I P_{p s}\right)$ is not known, but spore release is triggered by high humidity, e.g., caused by dew, fog, or rain $(3,11,25)$. The infectious period was fixed at $75^{\circ} \mathrm{C}$-day, as for the pycnidia (Table 2).

The model simulates the epidemic from crop emergence when only primary leaves are visible. If the area of a primary leaf at this time is $5 \mathrm{~cm}^{2}$ and the plant density is 400 plants per $\mathrm{m}^{2}$, the initial total healthy leaf area is $H L A T_{I}=0.2 \mathrm{~m}^{2}$ of leaf per $\mathrm{m}^{2}$ of ground. This leaf area is placed in age class $1\left(\mathrm{HLA}_{1}\right)$ at time $T=0$. The rate of ascospore immigrants $(I M M)$ into the field was fixed at $10^{-5 \circ} \mathrm{C}-$ day $^{-1}$. This was sufficiently low that the majority of inoculum came from within the crop as soon as the epidemic got started, as is the case in natural epidemics (29).

The expolinear growth model requires a number of parameters (Tables 2 and 3). The maximum healthy leaf area attainable $\left(H L A T_{M}\right)$ was assumed to be $6 \mathrm{~m}^{2}$ of leaf per $\mathrm{m}^{2}$ of ground. The other parameters were found or estimated from the literature, to ensure that the resulting crop growth curve without disease looked reasonable. The constant $(C)$ was derived as the product of the three parameters maximum absolute growth rate of crop biomass, parameter for partitioning to leaf dry weight, and specific leaf area. A typical value for the maximum absolute growth rate of crop biomass is $20 \mathrm{~g} \mathrm{~m}^{-2}$ day $^{-1}$ (12), with an average temperature of $15^{\circ} \mathrm{C}$, which corresponds to approximately $1.5 \mathrm{~g} \mathrm{~m}^{-2 \circ} \mathrm{C}$-day ${ }^{-1}$. Typical values of partitioning to leaf dry weight and specific leaf area are 0.5 and $0.02 \mathrm{~m}^{2} \mathrm{~g}^{-1}$, respectively (12), and therefore, $C=$ $0.015^{\circ} \mathrm{C}$-day ${ }^{-1}$. The light extinction coefficient $(K)$ is typically between 0.3 for erectophile canopies and 0.9 for planophile canopies (13). Here, 0.4 was chosen as a reasonable value for wheat, having an erect growth habit. The product of $C \times K$ is the potential relative growth rate for the early exponential phase of host growth.

Leaf area growth was assumed to stop at $1,500^{\circ} \mathrm{C}$-day $\left(T_{s}\right)$. O'Callaghan et al. (22) found leaf lifetimes of 1,000, 1,000, 950, and $700^{\circ} \mathrm{C}$-day for leaf one (flag), two, three, and four, respectively. The lower leaves are assumed to have shorter lives in thermal time, and the mean leaf lifetime $\left(T_{l}\right)$ in the model was set to $700^{\circ} \mathrm{C}$-day. The crop is ready for harvest at approximately $2,500^{\circ} \mathrm{C}$-day.

\section{RESULTS}

The parameters that influenced the severity of the epidemic $\left(\mathrm{AUDPC}_{2,500}\right)$ the most were multiplication efficiency for pycnidia and latent period for pycnidia. They scarcely interacted with the remaining parameters in the model (data not shown), and data from simulations with a single set of values are presented, $M E_{p y}=$ $0.05^{\circ} \mathrm{C}$-day ${ }^{-1}$ and $L P_{p y}=350^{\circ} \mathrm{C}$-day.

The model for host growth led to an early exponential growth of host leaf area, later entering a linear phase, and finally the healthy leaf area rapidly declined (Fig. 2), depending on how severe an epidemic was simulated. Due to the long latent period for this fungus, big areas with latent disease and immature pseudothecia were possible. The longer latent period for pseudothecia meant that area with pycnidia appeared well before area with pseudothecia (Fig. 2).

The development of a number of auxiliary variables over the season (Table 1) was simulated for varying values of contact rate $\left(C O N=2\right.$ and $6^{\circ} \mathrm{C}$-day $\left.{ }^{-1}\right)$, ratio between multiplication efficiencies $\left(R_{M E}=0.1\right.$ and 0.5$)$, and ratio between latent periods

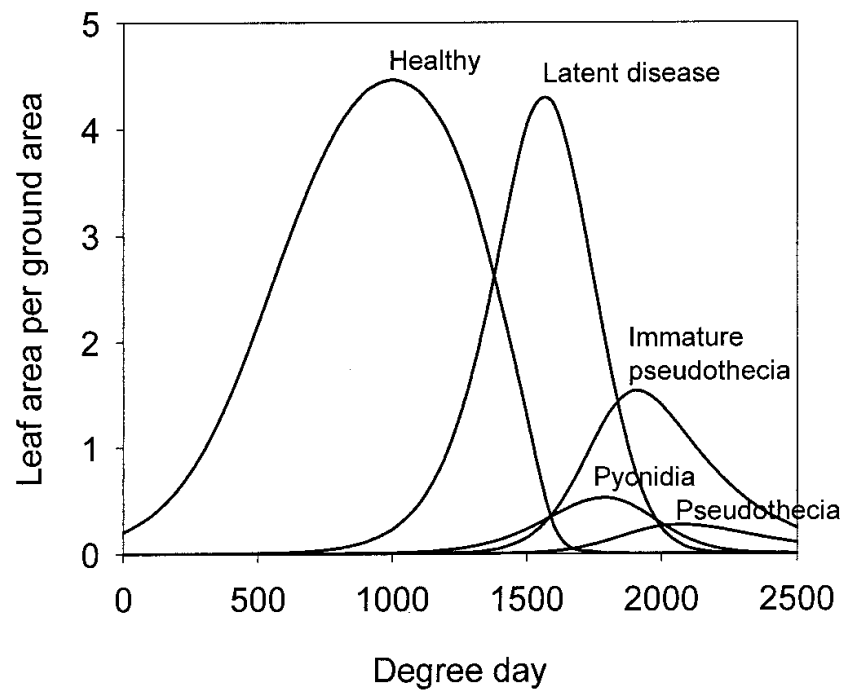

Fig. 2. Typical simulation from the model simulating the epidemic development of the disease septoria tritici blotch caused by the fungus Mycosphaerella graminicola. Total plant leaf area (TOT) is divided into (i) healthy leaf area (HLAT), (ii) leaf area with latent disease $\left(\operatorname{LDIT}_{a+s}\right)$, (iii) leaf area with immature pseudothecia (IMST), (iv) leaf area with pycnidia (IPY ${ }_{a+s}$ ), and (v) leaf area with pseudothecia (IPS). Parameter values: contact rate $(C O N)=$ $2^{\circ} \mathrm{C}_{\text {-day }}{ }^{-1}$; multiplication efficiency for pycnidia $\left(M E_{p y}\right)=0.05^{\circ} \mathrm{C}_{\text {-day }}{ }^{-1}$; latent period for pycnidia $\left(L P_{p y}\right)=350^{\circ} \mathrm{C}$-day; ratio between latent period for pseudothecia and pycnidia $\left(R_{L P}\right)=2.0$; and ratio between multiplication efficiency for pseudothecia and pycnidia $\left(R_{M E}\right)=0.4$. 
$\left(R_{L P}=2\right.$ and 3$)$. The ratios between latent periods and multiplication efficiencies had practically no influence on the pycnidiospore equivalents in the model, and the curves from runs where these two parameters were varied fell on top of each other
(Fig. 3A). A higher contact rate resulted in a considerable reduction in pycnidiospore equivalents. Ascospore equivalents were influenced by all three parameters. Higher contact rate and ratio between multiplication efficiencies gave more ascospore
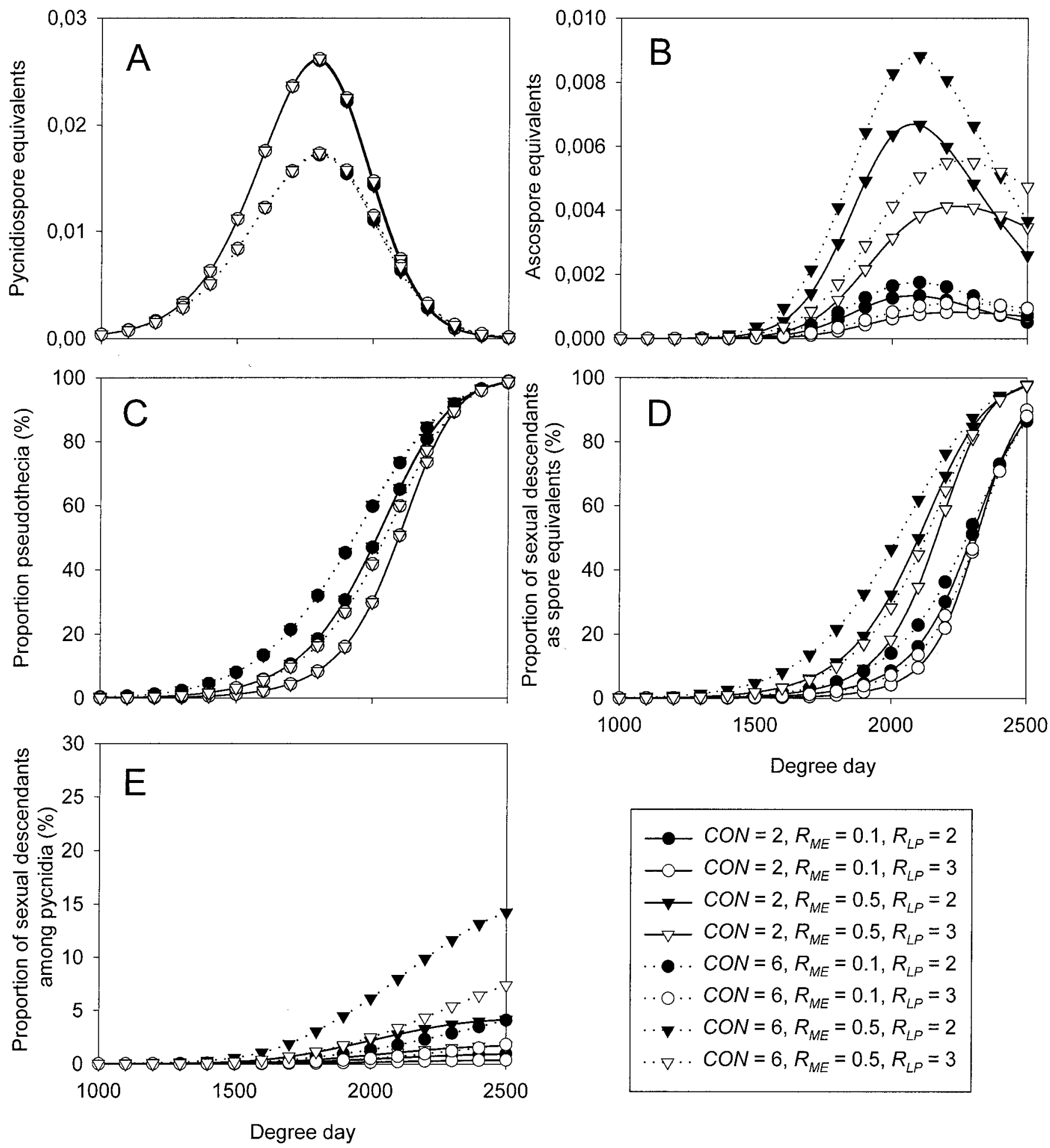

Degree day

$$
\begin{aligned}
& \longrightarrow C O N=2, R_{M E}=0.1, R_{L P}=2 \\
& \multimap-C O N=2, R_{M E}=0.1, R_{L P}=3 \\
& \longrightarrow C \operatorname{CON}=2, R_{M E}=0.5, R_{L P}=2 \\
& \longrightarrow-C O N=2, R_{M E}=0.5, R_{L P}=3 \\
& \cdots \cdots C O N=6, R_{M E}=0.1, R_{L P}=2 \\
& \cdots O C O N=6, R_{M E}=0.1, R_{L P}=3 \\
& \cdots \nabla C O N=6, R_{M E}=0.5, R_{L P}=2 \\
& \cdots \nabla \cdot C O N=6, R_{M E}=0.5, R_{L P}=3
\end{aligned}
$$

Fig. 3. Simulation results from the model for epidemic development of the disease septoria tritici blotch, caused by the fungus Mycosphaerella graminicola. The development is shown from $1,000^{\circ} \mathrm{C}$-day to the end of the season for a number of variables. A and $\mathbf{B}$, Pycnidiospore and ascospore equivalents of $M$. graminicola. Spore equivalents are calculated as the multiplication efficiency of a particular spore type multiplied by the infectious leaf area producing the particular type of spore. C, The proportion of infectious area that is occupied by pseudothecia. D, The proportion of sexual descendants of the immigrant population as spore equivalents. This is a measure of the proportion of potential new infections that would be initiated by spores, which are sexual descendants of the immigrants. E, The proportion of the infectious area with pycnidia that is occupied by sexual descendants of the immigrant population. Parameter values: contact rate $(C O N)$ and ratio between the multiplication efficiencies $\left(R_{M E}\right)$ for pseudothecia and pycnidia and the ratio between latent periods $\left(R_{L P}\right)$ for pseudothecia and pycnidia varied; multiplication efficiency for pycnidia $\left(M E_{p y}\right)=0.05^{\circ} \mathrm{C}$-day ${ }^{-1}$; and latent period for pycnidia $\left(L P_{p y}\right)=350^{\circ} \mathrm{C}$-day. Note the different scales between panels A and B. 
equivalents, whereas a greater ratio between latent periods gave fewer (Fig. 3B). The level of the ascospore equivalents peaked before harvest. The time for this peak was delayed at the high ratio between latent periods $\left(R_{L P}=3\right)$ compared with the lower ratio $\left(R_{L P}=2\right)$. Higher contact rate resulted in an earlier increase in the proportion of infectious leaf area that was occupied by pseudothecia, whereas a higher ratio between latent periods resulted in a delayed increase (Fig. 3C). The ratio between the multiplication efficiencies had no influence on the proportion of pseudothecia.

The two measures of sexual descendants, proportion of sexual descendants as spore equivalents and proportion of sexual descendants among pycnidia, were affected by the three parameters in much the same way (Fig. 3D and E). A higher contact rate resulted in a higher proportion of sexual descendants, as did a higher ratio between multiplication efficiencies, whereas a higher ratio between latent periods resulted in a lower proportion of sexual descendants. Sexual descendants, as spore equivalents, increased to approximately 80 to $100 \%$ for all parameter combinations by the end of the season. The final proportion of sexual descendants among pycnidia varied between 0.4 and $14 \%$, depending on parameter values.

A period of unfavorable weather for pycnidiospore dispersal was simulated by setting the multiplication efficiency for pycnidia to zero for a period of $200^{\circ} \mathrm{C}$-day (from 1,400 to $1,600^{\circ} \mathrm{C}$-day), while the multiplication efficiency for pseudothecia was maintained at its previous level. This resulted in a higher proportion of sexual descendants among pycnidia, between 1.1 and $27 \%$ (Fig. 4).

$\mathrm{AUDPC}_{2,500}$ was calculated for a number of different combinations of ratio between multiplication efficiencies for pseudothecia and pycnidia, ratio between latent periods for pseudothecia and pycnidia, and contact rates (Fig. 5). The AUDPC 2,500 varied from 730 to $770^{\circ} \mathrm{C}-$ day $^{-1}$ for the different parameter combinations. The two ratios had a small influence on the severity of the epidemic. A greater ratio between multiplication efficiencies and lower ratio between latent periods gave a greater $\mathrm{AUDPC}_{2,500}$. Higher contact rate reduced the severity of the epidemic slightly, by approximately $5 \%$, from a contact rate of 0 to a contact rate of $6^{\circ} \mathrm{C}$-day. Simulation with a period of unfavorable weather for pycnidiospore dispersal, as described previously, reduced the $\mathrm{AUDPC}_{2,500}$ from being in the interval 730 to $770^{\circ} \mathrm{C}$-day to the interval 640 to $700^{\circ} \mathrm{C}$-day. The effect of the ratios between multiplication efficiency and latent periods was still negligible (data not shown). An epidemic in which both the multiplication efficiency for pycnidia and for pseudothecia were set to zero resulted in an $\mathrm{AUDPC}_{2,500}$ of $15^{\circ} \mathrm{C}$-day. This disease was exclusively caused by immigrant ascospores making healthy leaf area diseased at a rate of $I M M=10^{-5 \circ} \mathrm{C}-$ day $^{-1}$.

For the same parameter combinations, the proportion of sexual descendants among pycnidia at $1,500,2,000$, and $2,500^{\circ} \mathrm{C}$-day was calculated. The proportion increased from 1,500 to $2,500^{\circ} \mathrm{C}$-day, but the influence of the parameters was the same, independent of the time in the growing season, and only the data for $2,500^{\circ} \mathrm{C}$-day are shown (Fig. 6). Higher contact rate resulted in more sexual descendants; the same was the case for higher ratios between multiplication efficiencies, but a higher ratio between latent periods resulted in a lower proportion of sexual descendants.

\section{DISCUSSION}

The purpose of this study was to investigate the influence of pseudothecia on genetic recombination and epidemic development in populations of $M$. graminicola, by simulation of a mathematical model. The model approach was chosen, because an estimate of the level of genetic recombination in $M$. graminicola populations is difficult to obtain experimentally $(2,32,33)$ and it is difficult to compare the importance of the two spore types for the epidemic development from published field data.

The results of this simulation study suggest that populations of M. graminicola could consist of fairly high proportions of sexual descendants at the end of the growing season, especially in seasons with long periods of unfavorable weather for the dispersal of pycnidiospores. Furthermore, ascospores have a negligible influence on the epidemic development.

Epidemic development. Changing the ratio between the multiplication efficiencies for pseudothecia and pycnidia $\left(R_{M E}\right)$ and the ratio between their latent periods $\left(R_{L P}\right)$, while keeping the multiplication efficiency $\left(M E_{p y}\right)$ and latent period $\left(L P_{p y}\right)$ for pycnidia fixed, was a convenient way of simulating the differences in the epidemiological parameters for the two stages of the fungus. From the limited influence of the two ratios $R_{L P}$ and $R_{M E}$ on $\mathrm{AUDPC}_{2,500}$ (Fig. 5), it is concluded that new infections initiated by ascospores contribute very little to the severity of the epidemic. However, the

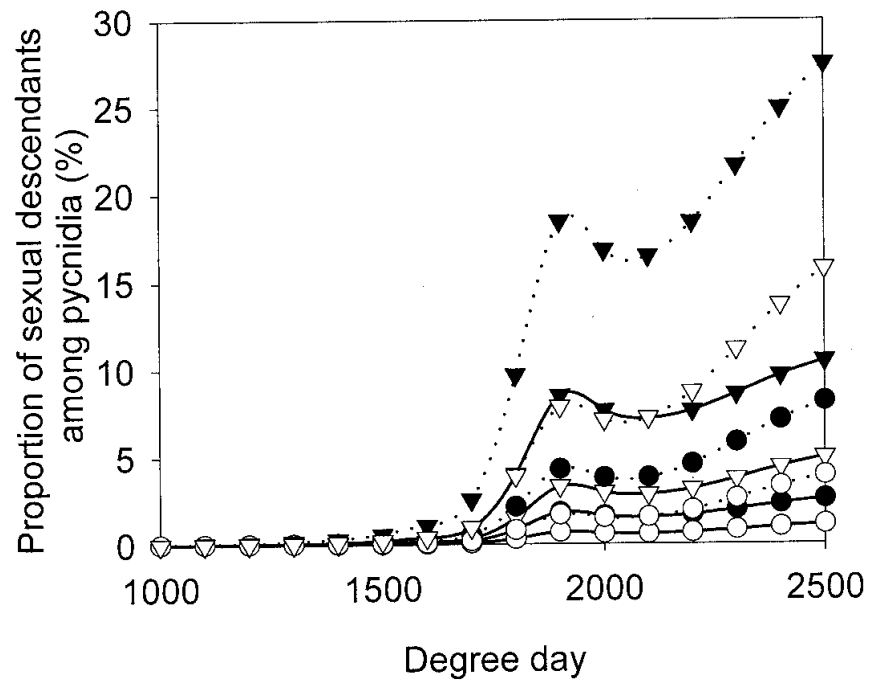

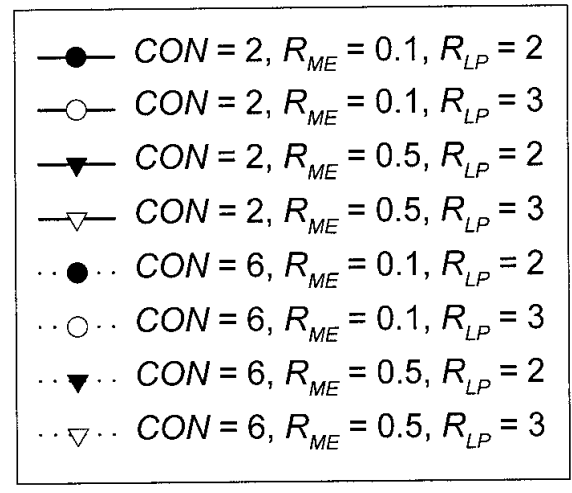

Degree day

Fig. 4. Simulation results from the model for epidemic development of the disease septoria tritici blotch, caused by the fungus Mycosphaerella graminicola. A period of $200^{\circ} \mathrm{C}$-day (from 1,400 to $1,600^{\circ} \mathrm{C}$-day) of unfavorable weather for dispersal of pycnidiospores is simulated. The development is shown from $1,000^{\circ} \mathrm{C}$-day to the end of the season for the proportion of the infectious area with pycnidia that is occupied by sexual descendants of the immigrants. Parameter values: contact rate $(C O N)$ and ratio between the multiplication efficiencies $\left(R_{M E}\right)$ for pseudothecia and pycnidia and the ratio between latent periods $\left(R_{L P}\right)$ for pseudothecia and pycnidia varied; multiplication efficiency for pycnidia $\left(M E_{p y}\right)=0.05^{\circ} \mathrm{C}$-day ${ }^{-1}$; and latent period for pycnidia $\left(L P_{p y}\right)=350^{\circ} \mathrm{C}$-day. 
relative importance of ascospores compared with pycnidiospores is influenced by weather conditions. Because ascospores do not need rain for dispersal, as pycnidiospores do, disease progress caused by ascospores is likely to occur more often than disease progress caused by pycnidiospores. This is equivalent to an increase in the ratio $R_{M E}$ in the model, which did not have much effect on $\mathrm{AUDPC}_{2,500}$. Even in a case when a period during the growing season without multiplication of disease due to pycnidiospores was simulated, there was little effect of ascospores on the severity of the epidemic (data not shown). These results suggest that a detailed modeling of the dispersal process, including the effect of weather, is unlikely to affect the conclusions made in this paper. The reason is the longer latent period and the lower multiplication efficiency for pseudothecia compared with pycnidia, which causes new infections by leaf area occupied by pseudothecia to occur later and in lower numbers than infections caused by leaf area occupied by pycnidia.

The results of the simulations are in agreement with Danish field observations. Here pseudothecia appeared in large numbers by the end of July, too late in the season for ascospores to influence the epidemic (8). A similar conclusion was reached in Argentine, where both pycnidiospores and ascospores were trapped on microscope slides within fields (6). Pycnidiospores were always present, and the number of ascospores caught peaked at the end of the growing season.

Because the effect of ascospores on the severity of the epidemic was small, it is probably correct to disregard the ascospores when simulating the development of $M$. graminicola during one growing season, as was done by O'Callaghan et al. (22).

Sexual descendants. Ascospores are produced sexually from mating between two different mating types, resulting in genetic recombination. If this recombination has a significant influence on the genetic composition of the population, a considerable proportion of the population would be sexual descendants at the end of the growing season. For plausible values of ratio between multiplication efficiencies $\left(R_{M E}<0.5\right)$ and ratio between latent periods $\left(R_{L P}>2\right)$, the proportion of sexual descendants among pycnidia at $2,500^{\circ} \mathrm{C}$-day reached a maximum of 12 to $15 \%$ at the highest contact rate, $C O N=6.0^{\circ} \mathrm{C}$-day ${ }^{-1}$ (Figs. $3 \mathrm{E}$ and 6). Simulation runs, including a period of zero multiplication by pycnidia due to

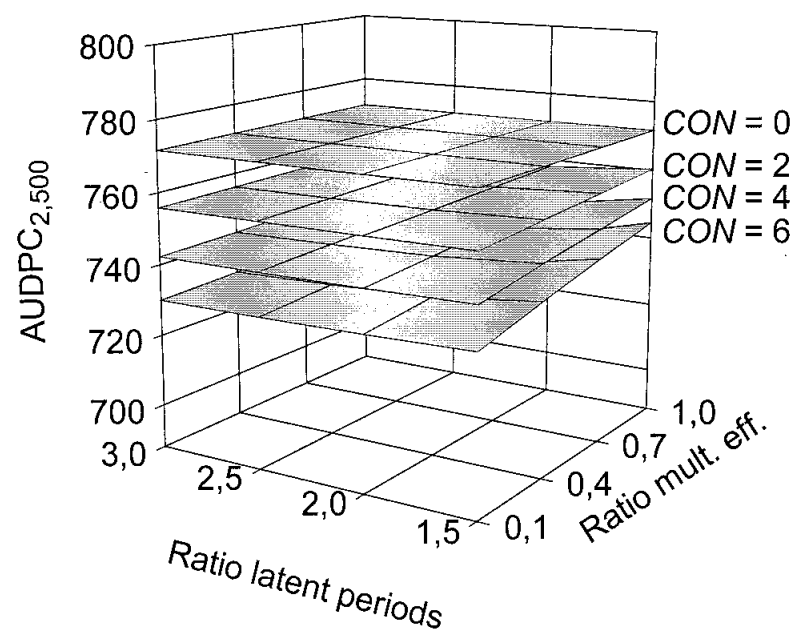

Fig. 5. Simulation results from the model for epidemic development of the disease septoria tritici blotch, caused by the fungus Mycosphaerella graminicola. Area under the disease progress curve at $2,500^{\circ} \mathrm{C}$-day $\left(\mathrm{AUDPC}_{2,500}\right)$ is shown for four values of ratio between latent periods for pseudothecia and pycnidia $\left(R_{L P}=1.5,2.0,2.5\right.$, and 3.0$)$, ratio between multiplication efficiency for pseudothecia and pycnidia $\left(R_{M E}=0.1,0.4,0.7\right.$, and 1.0), and contact rate $\left(C O N=0,2,4\right.$, and $6^{\circ} \mathrm{C}$-day $\left.{ }^{-1}\right)$. Multiplication efficiency for pycnidia $\left(M E_{p y}\right)=0.05^{\circ} \mathrm{C}-$ day $^{-1}$; and latent period for pycnidia $\left(L P_{p y}\right)=$ $350^{\circ} \mathrm{C}$-day. unfavorable weather for dispersal of pycnidiospores, approximately doubled the level of sexual descendants among pycnidia (Figs. 3E and 4). The increase in sexual descendants after a simulated dry period is brought about by the exclusive sexual reproduction during this period. Although the disease hardly progresses on the ascospores alone, such a period results in a high proportion of sexual descendants for the subsequent faster disease development caused by pycnidiospores. Such periods with dry weather preventing the spread of pycnidiospores but with sufficient moisture to let pseudothecia sporulate are likely to be common. Consequently, the proportion of sexual descendants at the end of the growing season may be considerable, perhaps 20 to $30 \%$ of the population. An attempt to estimate this proportion experimentally has been made using artificial inoculation of field plots with 10 isolates, followed by sampling of the population in the plots over the season (32). Using a combination of DNA fingerprints and discrete restriction fragment length polymorphism loci, the sampled isolates were allocated to one of three classes: asexual descendants of the initial 10 isolates, sexual descendants of the 10 isolates, and immigrants from outside. The proportion of sexual descendants at the end of the season was estimated to be $24 \%$. However, the reliability of the estimation procedure has been questioned $(2,33)$. Nevertheless, this estimate would be in reasonable agreement with the predictions of our simulation studies.

The proportion of infectious leaf area occupied by pseudothecia and the proportion of sexual descendants measured as spore equivalents (i.e., the proportion of potential new infections that would be initiated by spores that are sexual descendants of the immigrants) reached very high levels, up to approximately $100 \%$ at the end of season (Fig. 3C and D). This is due to the long latent period for pseudothecia compared with pycnidia and the fact that the infectious periods are assumed identical for pycnidia and pseudothecia. At the end of the season when no more healthy leaf area is available for new infections, the remaining pycnidia will be exhausted before the pseudothecia, and the proportion of pseudothecia will increase toward 100\% (Figs. 2 and 3A and B). The potential for new infections by spores that are sexual descendants increased rapidly toward the end of the season (Fig. 3D). A high proportion of these ascospores will be lost because insufficient healthy leaf area is available for infection and because the latent

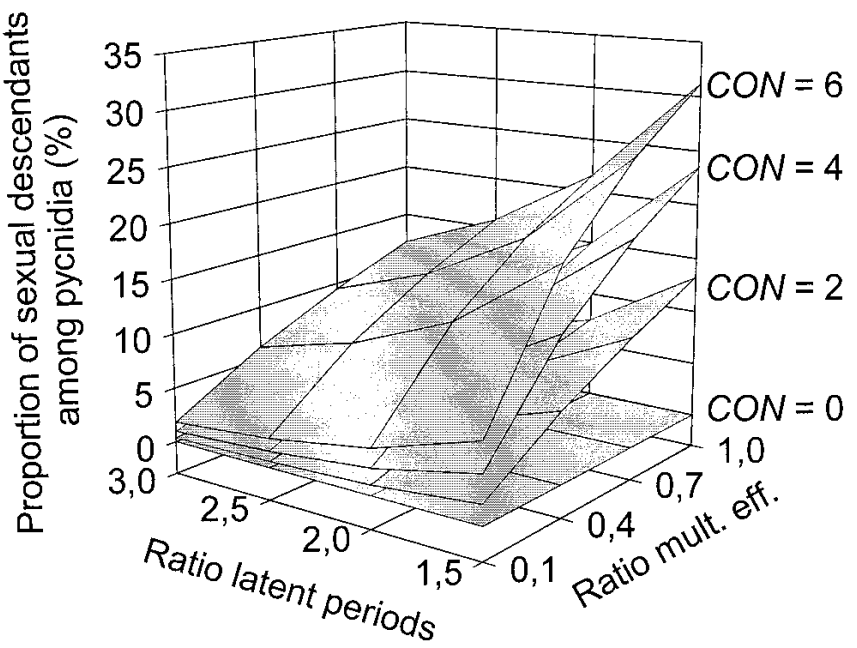

Fig. 6. Simulation results from the model for epidemic development of the disease septoria tritici blotch, caused by the fungus Mycosphaerella graminicola. The proportion of the infectious area with pycnidia that is occupied by sexual descendants of the immigrant population at $2,500^{\circ} \mathrm{C}$-day is shown for four values of ratio between latent periods for pseudothecia and pycnidia $\left(R_{L P}=1.5,2.0,2.5\right.$, and 3.0$)$, ratio between multiplication efficiency for pseudothecia and pycnidia $\left(R_{M E}=0.1,0.4,0.7\right.$, and 1.0), and contact rate $\left(C O N=0,2,4\right.$, and $\left.6^{\circ} \mathrm{C}-d_{a y}^{-1}\right)$. Multiplication efficiency for pycnidia $\left(M E_{p y}\right)=0.05^{\circ} \mathrm{C}_{\text {-day }}^{-1}$; and latent period for pycnidia $\left(L P_{p y}\right)=350^{\circ} \mathrm{C}$-day. 
period is so long that symptoms would only appear around harvest. If all these spores could have infected and produced pycnidia, the proportion of sexual descendants among pycnidia (Fig. 3E) would also have increased toward $100 \%$.

The simulation results are generally in agreement with Danish field observations over 2 years (8). In a field plot, the proportion of infectious $M$. graminicola fruit bodies identified as pseudothecia on leaves one (flag) to four in 1998, reached maximum levels of 70 to $100 \%$ at the end of the growing season. At the same time in 1999, 40 to $70 \%$ of infectious M. graminicola fruit bodies was identified as pseudothecia on leaf two to four, but only $3 \%$ on leaf one (flag).

In conclusion, the results obtained concerning the proportion of sexual descendants suggest that there is a potential for recombination over the growing season affecting the genetic structure of the population. This could have implications for how fast the pathogen population adapts to resistant cultivars, as demonstrated in a genetic model study (8).

Assumptions on multiplication. The ratio between multiplication efficiencies $\left(R_{M E}\right)$ reflects the difference in spore production, potential differences in infection efficiency, and the different mechanisms of dispersal for ascospores and pycnidiospores. For the following reasons, plausible values of $R_{M E}$ were assumed to be less than 0.5. (i) Ascospores are airborne, consequently a high proportion of released ascospores may be lost on the ground. The splash-dispersed pycnidiospores move over the leaf surface in a water film, and may move from plant to plant or upward in the crop canopy by direct contact between infected plant parts $(20,29)$. Therefore, a smaller proportion of pycnidiospores compared with ascospores may be lost. (ii) Preliminary results of infection experiments suggest that the infection efficiency of ascospores and pycnidiospores are not widely different (8). (iii) Pseudothecia have a limited spore production capacity compared with pycnidia.

Assumptions on immigration. Throughout the growing season ascospores were assumed to be immigrating from outside, and this was modeled as healthy leaf area becoming diseased at the rate $I M M$. Ths assumption is based on results from trapping of ascospores in the U.K. $(17,25,28)$. Here, ascospores were present all year round. However, the number of spores trapped was variable over the 3 years that data were presented, and for long periods in each of the 3 years, none or very few spores were trapped (17). Therefore, the constant rate of immigrants over the whole season in the model is an approximation. The disease developed from these immigrants only, i.e., when no multiplication of the disease in the crop was allowed, gave rise to an $\mathrm{AUDPC}_{2,500}$ of $15^{\circ} \mathrm{C}$-day. Although the value of IMM does influence the severity of the epidemic, it is not likely to influence the conclusions in this paper regarding the relative contribution of pycnidiospores and ascospores to the epidemic development and the proportion of sexual descendants.

Assumptions on mating. The primary infections are, thus, initiated by an ascospore population in which the two mating types occur in approximately equal frequency, implying that during the season the mating types are also likely to occur in approximately equal frequency. This has been supported by screening populations with markers for the mating type locus, showing approximately equal frequency of the two mating types in natural populations (G. H. J. Kema, personal communication). In a survey with molecular markers, different genotypes were found in different lesions on the same leaf in $92 \%$ of comparisons (21), suggesting random distribution of the two mating types on the leaf. Consequently, it was assumed when developing the model that the two mating types occur in equal frequency in the population and that they are randomly distributed over the host leaf area.

Mating in fungi may involve the production of microspores that are able to fertilize the female organ, the ascogonium of the opposite mating type. In this case, the two mating types do not have to meet in the leaf, but microspores could be moved over the leaf in a water film, making high contact rates possible, i.e., individuals far apart are able to mate. However, in many ascomycetes there are no microspores involved in the mating process. Instead, mating takes place by fusion of ordinary or specialized hyphae (31). Hyphae of $M$. graminicola grow inside the leaf, and the pseudothecia are located under the epidermis $(5,16,19,24)$. Microspores are, thus, unlikely to be involved in the mating, because the mating must occur inside the leaf. Consequently, it was assumed in the model that mating in $M$. graminicola is by contact between hyphae of opposite mating type, inside the leaf.

In field samples from Denmark, pseudothecia were only found on leaf layers with an average disease severity of more than $40 \%$, suggesting that the production of pseudothecia depend on a high infection density (8). Matings in the model take place at a rate depending on the infection density, defined as the latent diseased leaf area in the last age class relative to the total area. The exact time when matings take place depends on the mechanism of mating and on the age at which individuals of the fungus are able to mate, and that is unknown. However, if matings are made to depend on a different relative leaf area than described above, it will only change the numerical value of the contact rate, the qualitative behavior of the system is not likely to be affected.

The contact rate can be interpreted as a parameter controlling how resources are re-allocated from the production of pycnidia to production of pseudothecia at a certain infection density. The result of this model structure is that the more sexual reproduction that is allowed (higher contact rate) the less disease develops (Fig. 5). The relative reduction in $\mathrm{AUDPC}_{2,500}$ was small when sexual reproduction was included, $5 \%$ for a contact rate of $6^{\circ} \mathrm{C}-$ day $^{-1}$. Contact rates of more than $6^{\circ} \mathrm{C}$-day ${ }^{-1}$ resulted in a big area with pseudothecia compared with the area with pycnidia (data not shown). This seems unlikely because the production of a pseudothecium requires contact between two individuals of different mating type. Therefore, a contact rate of 6 is assumed to be the maximum.

\section{ACKNOWLEDGMENTS}

The work was financed by a Ph.D. grant from The Royal Veterinary and Agricultural University, Denmark. We thank L. Munk for many discussions on the biology of M. graminicola in relation to the model and V. Andreasen for comments and suggestions on earlier versions of the manuscript. The work was stimulated by discussions in working groups of the European Cooperation in the field of Scientific and Technical Research (COST) Action 817: Population studies of airborne pathogens on cereals as a means of improving strategies for disease control.

\section{LITERATURE CITED}

1. Anderson, R. M., and May, R. M. 1979. Population biology of infectious diseases: Part I. Nature 280:361-367.

2. Brown, J. K. M. 2000. Estimation of rates of recombination and migration in populations of plant pathogens. Phytopathology 90:320-323.

3. Brown, J. S., Kellock, A. W., and Paddick, R. G. 1978. Distribution and dissemination of Mycosphaerella graminicola (Fuckel) Schroeter in relation to the epidemiology of speckled leaf blotch of wheat. Aust. J. Agric. Res. 29:1139-1145.

4. Chen, R. S., and McDonald, B. A. 1996. Sexual reproduction plays a major role in the genetic structure of populations of the fungus Mycosphaerella graminicola. Genetics 142:1119-1127.

5. Cohen, L., and Eyal, Z. 1993. The histology of processes associated with the infection of resistant and susceptible wheat cultivars with Septoria tritici. Plant Pathol. 42:737-743.

6. Cordo, C. A., Simon, M. R., Perelló, A. E., and Alippi, H. E. 1999. Spore dispersal of leaf blotch pathogens of wheat (Mycosphaerella graminicola and Septoria tritici). Pages 98-101 in: Septoria and Stagonospora Diseases of Cereals: A Compilation of Global Research. M. Van Ginkel and J. Krupinsky, eds. International Maize and Wheat Improvement Center, Mexico, D.F.

7. Djurle, A., and Yuen, J. E. 1991. A simulation model for Septoria nodorum in winter wheat. Agric. Syst. 37:193-218. 
8. Eriksen, L. 2000. The influence of sexual reproduction on the structure of populations of Mycosphaerella graminicola in relation to durability of resistance. Ph.D. thesis, The Royal Veterinary and Agricultural University, Denmark.

9. Eyal, Z. 1971. The kinetics of pycnospore liberation in Septoria tritici. Can. J. Bot. 49:1095-1099.

10. Gallagher, J. N. 1979. Field studies of cereal leaf growth. I. Initiation and expansion in relation to temperature and ontogeny. J. Exp. Bot. 30:625-636.

11. Garcia, C., and Marshall, D. 1992. Observations on the ascogenous stage of Septoria tritici. Mycol. Res. 96:65-70.

12. Goudriaan, J. 1994. Using the expolinear growth equation to analyze resource capture. Pages 99-110 in: Resource Capture by Crops. J. L. Monteith, R. K. Scott, and M. H. Unsworth, eds. Nottingham University Press, Nottingham.

13. Goudriaan, J., and Monteith, J. L. 1990. A mathematical function for crop growth based on light interception and leaf area expansion. Ann. Bot. 66:695-701

14. Goudriaan, J., and van Roermund, H. J. W. 1989. Modeling of aging, development, delays and dispersion. Pages 47-79 in: Simulation and Systems Management in Crop Protection. R. Rabbinge, S. A. Ward, and H. H. van Laar, eds. Centre for Agricultural Publishing and Documentation (PUDOC), Wageningen.

15. Gough, F. J. 1978. Effect of wheat host cultivars on pycnidiospore production by Septoria tritici. Phytopathology 68:1343-1345.

16. Hilu, H. M., and Bever, W. M. 1957. Inoculation, oversummering, and suscept-pathogen relationship of Septoria tritici in triticum species. Phytopathology 47:474-480.

17. Hunter, T., Coker, R. R., and Royle, D. J. 1999. The teleomorph stage, Mycosphaerella graminicola, in epidemics of septoria tritici blotch on winter wheat in the UK. Plant Pathol. 48:51-57.

18. Kema, G. H. J., Verstappen, E. C. P., Todorova, M., and Waalwijk, C. 1996. Successful crosses and molecular tetrad and progeny analysis demonstrate heterothallism in Mycosphaerella graminicola. Curr. Genet. 30:251-258.

19. Kema, G. H. J., Yu, D., Rijkenberg, F. H. J., Shaw, M. W., and Baayen, R. P. 1996. Histology of the pathogenesis of Mycosphaerella graminicola in wheat. Phytopathology 86:777-786.

20. Lovell, D. J., Parker, S. R., Hunter, T., Royle, D. J., and Coker, R. R. 1997. Influence of crop growth and structure on the risk of epidemics by Mycosphaerella graminicola (Septoria tritici) in winter wheat. Plant
Pathol. 46:126-138.

21. McDonald, B. A., and Martinez, J. P. 1990. DNA restriction fragment length polymorphisms among Mycosphaerella graminicola (anamorph Septoria tritici) isolates collected from a single wheat field. Phytopathology 80:1368-1373.

22. O'Callaghan, J. R., Dahab, M. H., Hossain, A. H. M. S., and Wyseure, G. C. L. 1994. Simulation of Septoria tritici-winter wheat interactions. Comput. Electron. Agric. 11:293-308.

23. Rapilly, F. 1979. Simulation of an epidemic of Septoria nodorum Berk. on wheat in relation to the possibility of horizontal resistance. Eur. Mediterr. Plant Prot. Organ. Bull. 9:243-250.

24. Sanderson, F. R. 1976. Mycosphaerella graminicola (Fuckel) Sanderson comb. nov., the ascogenous state of Septoria tritici Rob. apud Desm. N. Z. J. Bot. 14:359-360.

25. Sanderson, F. R., and Hampton, J. G. 1978. Role of the perfect states in the epidemiology of the common Septoria diseases of wheat. N. Z. J. Agric. Res. 21:277-281.

26. Shaw, M. W. 1990. Effects of temperature, leaf wetness and cultivar on the latent period of Mycosphaerella graminicola on winter wheat. Plant Pathol. 39:255-268.

27. Shaw, M. W. 1999. Population dynamics of Septoria in the crop ecosystem. Pages 82-95 in: Septoria on Cereals: A Study of Pathosystems. J. A Lucas, P. Bowyer, and H. M. Anderson, eds. CABI Publishing, Cambridge.

28. Shaw, M. W., and Royle, D. J. 1989. Airborne inoculum as a major source of Septoria tritici (Mycosphaerella graminicola) infections in winter wheat crops in the UK. Plant Pathol. 38:35-43.

29. Shaw, M. W., and Royle, D. J. 1993. Factors determining the severity of epidemics of Mycosphaerella graminicola (Septoria tritici) on winter wheat in the UK. Plant Pathol. 42:882-899.

30. Thomas, M. R., Cook, R. J., and King, J. E. 1989. Factors affecting development of Septoria tritici in winter wheat and its effect on yield. Plant Pathol. 38:246-257.

31. Webster, J. 1993. Introduction to Fungi. Cambridge University Press, Cambridge.

32. Zhan, J., Mundt, C. C., and McDonald, B. A. 1998. Measuring immigration and sexual reproduction in field populations of Mycosphaerella graminicola. Phytopathology 88:1330-1337.

33. Zhan, J., Mundt, C. C., and McDonald, B. A. 2000. Estimation of rates of recombination and migration in populations of plant pathogens-A reply. Phytopathology 90:324-326.

\section{Erratum}

\section{Vol. 91, No. 3, 2001}

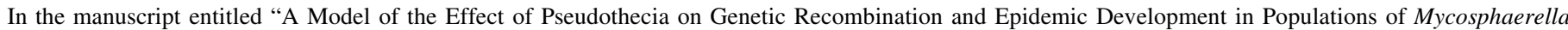
graminicola" by L. Eriksen, M. W. Shaw, and H. Østergård (Phytopathology 91:240-248), Table 3 is missing from the article and is included below.

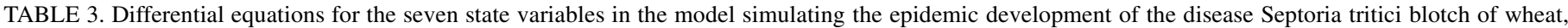
caused by pycnidiospores and ascospores of the fungus Mycosphaerella graminicola

\begin{tabular}{|c|c|c|}
\hline State variable & Differential equations for individual age classes ${ }^{a}$ & Equation no. \\
\hline $\mathrm{HLA}_{j}$ & $\begin{array}{l}d\left(\mathrm{HLA}_{1}\right) / d t=\mathrm{LPR}-\left[\left(15 / T_{l}\right)+M E_{p y} \times \mathrm{IPY}_{a+s}+M E_{p s} \times \mathrm{IPS}+I M M\right] \times \mathrm{HLA}_{1} \\
d\left(\mathrm{HLA}_{j=2-15}\right) / d t=\left(15 / T_{l}\right) \times\left(\mathrm{HLA}_{j-1}-\mathrm{HLA}_{j}\right)-\left(M E_{p y} \times \mathrm{IPY}_{a+s}+M E_{p s} \times \mathrm{IPS}+I M M\right) \times \mathrm{HLA}_{j}\end{array}$ & $\begin{array}{l}1 \\
2\end{array}$ \\
\hline NEC & $d(\mathrm{NEC}) / d t=\left(15 / T_{l}\right) \times \mathrm{HLA}_{15}$ & 3 \\
\hline $\mathrm{LDI}_{i, j}$ & $\begin{array}{l}d\left(\mathrm{LDI}_{a, 1}\right) / d t=M E_{p y} \times \mathrm{IPY}_{a} \times \mathrm{HLAT}+I M M \times \mathrm{HLAT}-\left(15 / L P_{p y}\right) \times \mathrm{LDI}_{a, 1} \\
d\left(\mathrm{LDI}_{s, 1}\right) / d t=\left(M E_{p y} \times \mathrm{IPY}_{s}+M E_{p s} \times \mathrm{IPS}\right) \times \mathrm{HLAT}-\left(15 / L P_{p y}\right) \times \mathrm{LDI}_{s, 1} \\
d\left(\mathrm{LDI}_{i, j=2-14}\right) / d t=\left(15 / L P_{p y}\right) \times\left(\mathrm{LDI}_{i, j-1}-\mathrm{LDI}_{i, j}\right) \\
d\left(\mathrm{LDI}_{i, 15}\right) / d t=\left(15 / L P_{p y}\right) \times\left(\mathrm{LDI}_{i, 14}-\mathrm{LDI}_{i, 15}\right)-\left[C O N \times \mathrm{LDI}_{a+s, 15} /(2 \times \mathrm{TOT})\right] \times \mathrm{LDI}_{i, 15}\end{array}$ & $\begin{array}{l}4 \\
5 \\
6 \\
7\end{array}$ \\
\hline $\mathrm{IPY}_{i}$ & $d\left(\mathrm{IPY}_{i}\right) / d t=\left(15 / L P_{p y}\right) \times \mathrm{LDI}_{i, 15}-\left(1 / I P_{p y}\right) \times \mathrm{IPY}_{i}$ & 8 \\
\hline $\mathrm{IMS}_{j}$ & $\begin{array}{l}d\left(\mathrm{IMS}_{1}\right) / d t=\left(C O N \times \mathrm{LDI}_{a+s, 15} /[2 \times \mathrm{TOT})\right] \times \mathrm{LDI}_{a+s, 15}-\left(2 / L P_{p s}\right) \times \mathrm{IMS}_{1} \\
d\left(\mathrm{IMS}_{2}\right) / d t=\left(2 / L P_{p s}\right) \times\left(\mathrm{IMS}_{1}-\mathrm{IMS}_{2}\right)\end{array}$ & $\begin{array}{r}9 \\
10\end{array}$ \\
\hline IPS & $d(\mathrm{IPS}) / d t=\left(2 / L P_{p s}\right) \times \mathrm{IMS}_{2}-\left(1 / I P_{p s}\right) \times \mathrm{IPS}$ & 11 \\
\hline $\mathrm{EXH}$ & $d(\mathrm{EXH}) / d t=\left(1 / I P_{p y}\right) \times \mathrm{IPY}_{a+s}+\left(1 / I P_{p s}\right) \times \mathrm{IPS}$ & 12 \\
\hline
\end{tabular}

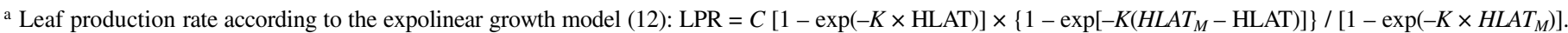

Leaf production rate $(\mathrm{LPR})=0$ for $t>T_{s}$. 